\title{
Comparative Analysis of Various Routing Protocol in MANET
}

\author{
Manveer Kaur \\ Department of computer science \\ Lovely Professional University \\ Phagwara, India
}

\author{
Ambrish Gangal \\ Department of computer science \\ Lovely Professional University \\ Phagwara, India
}

\begin{abstract}
The mobile ad hoc network is the self configuring and decentralized type of network. The network has not fixed topology as mobile nodes can move freely in the network. Due to dynamic type of topology and self configuring nature of mobile ad hoc network many issues get raised which are routing, security, quality of services and many more. In this paper, various types of routing protocols are reviewed with their advantages and disadvantages. The routing protocols are generally categorized as proactive, reactive and hybrid protocols. In these routing protocols energy and load balancing are main issues. There are many techniques for control the load on the network. The aim of this paper is to discuss about different types of techniques which is used for load balancing in ad hoc networks.
\end{abstract}

\section{Keywords}

Routing protocol, MANET, AODV, AOMDV, Load Balancing

\section{INTRODUCTION}

Mobile ad hoc network is a network made by number of nodes which are connected to each other via a wireless link. All the nodes are move here and there independently and there is no any centralized node. [1] Which nodes are in the range of each other then they can communicate directly. On the other hand the nodes which are not in the range can communicate indirectly and intermediate nodes between the communicating nodes are responsible for data forwarding. It is immortal network. Each and every node is acting like a router itself and there is no fixed topology. Node is entered in the network by forwarding the data to the destination, and so the decision of the nodes forward data is made at run time execution is based upon the network connectivity. Ad-hoc networks latest technique of wirelessly join for mobile hosts. it is a network which is used for emergency purpose. MANET's can easily establish because there is no need any access point. There are many types of MANET like iMANET (internet based mobile ad hoc network), VANET (vehicular ad hoc network), and SPANs (smart phone ad hoc network). In the network every node have some energy and moving speed with neighbor nodes whenever it is need with the help of some protocol which are routing protocol. Nodes are moveable so control the packet loss by load balance and make energy efficient.

\section{ROUTING PROTOCOL}

In ad hoc three types of routing protocol [2] Proactive (DSDV, OLSR, WRP), Reactive (DSR, TORA, AODV) and Hybrid (ZRP) routing protocol.
Table 1: Routing Protocol

\begin{tabular}{|l|l|l|l|l|}
\hline & $\begin{array}{l}\text { Types of } \\
\text { protocol }\end{array}$ & $\begin{array}{l}\text { Multicas } \\
\text { ting }\end{array}$ & $\begin{array}{l}\text { Routing } \\
\text { Metrics }\end{array}$ & $\begin{array}{l}\text { Load } \\
\text { Balancing }\end{array}$ \\
\hline DSDV & $\begin{array}{l}\text { Proactive } \\
\text { protocol }\end{array}$ & NO & Shortest path & NO \\
\hline OLSR & $\begin{array}{l}\text { Proactive } \\
\text { protocol }\end{array}$ & NO & Shortest path & NO \\
\hline WRP & $\begin{array}{l}\text { Proactive } \\
\text { protocol }\end{array}$ & NO & Hop count & NO \\
\hline DSR & $\begin{array}{l}\text { Reactive } \\
\text { protocol }\end{array}$ & NO & Shortest path & NO \\
\hline AODV & $\begin{array}{l}\text { Reactive } \\
\text { protocol }\end{array}$ & YES & $\begin{array}{l}\text { Fastest and } \\
\text { Shortest path }\end{array}$ & NO \\
\hline TORA & $\begin{array}{l}\text { Reactive } \\
\text { protocol }\end{array}$ & YES & $\begin{array}{l}\text { Directed } \\
\text { acyclic graph }\end{array}$ & NO \\
\hline ZRP & $\begin{array}{l}\text { Hybrid } \\
\text { protocol }\end{array}$ & YES & k hops & YES \\
\hline
\end{tabular}

a. Proactive routing protocol

Proactive protocol needs the information about the routing so they contain that information. They maintain the up to date information of the every node which is present in the network. Routing table is maintaining the information about the routes and sequentially updated when the topology change in the network. Proactive routing protocols are the protocols which are table driven. The routes are updated continuously and it uses an already available route when a node wants to route packets to another node, these protocols maintain routes to all the possible destinations even though a few of the routes may not be needed. The entire node in the network maintains tables of routes and when the network topology changes, updates are sent across the network.

\subsubsection{DSDV}

DSDV destination sequenced distance vector based upon the Bellman ford routing algorithm but the difference is that it avoid the routing loop in a mobile network. Sequence number phenomena is used so that the mobile host can identify stale route from new one routing table is updates during this criteria. In the DSDV mobile station is entered in the network constantly without any noise in the network. So that changes in table entry are very quickly and the data should be made rapidly to ensure that every node in the network can locate its neighbors. Each node sequentially broadcasts routing updates. DSD continuously update the routing information in the routing table, which use the more battery power but it is less use of the bandwidth when all nodes are free in the network

\subsubsection{OLSR}

Optimized Link State Routing (OLSR) is dynamic protocol which provides the link to the nodes for communication and 
control the link state information. OLSR used for at runtime calculate the routing table entry. OLSR use hello and topology control message using these individual nodes compute the next hop destination for all the nodes in the network and node select the multipoint relays for there exist path to next two hops so OLSR is different from the link state routing protocols.

\subsubsection{WRP}

WRP wireless routing protocol, this protocol belongs to the path finding algorithm. The count to infinity problem is avoided by forcing each node to check the predecessor information which is reported by its neighboring node. This method removes the looping situation when any link fails in the network. In WRP use the acknowledgment and other message for learning about its neighboring nodes. If node is idle mean it is not sending or receiving any packet then it send the hello message after some specific time so that it tells that it is within a connection and connection is healthy. If the node do not assume by the system that the link is broken and other node in the network does not considered that node while sending or receiving the data.

\section{b. Reactive routing protocol}

Reactive protocol is also called On Demand protocol which is use for routing purpose. They do not preserve routing activity or routing information at that area if there is no communication between nodes. It means route are creates only when the source node is present. In the network when node send a packet to another node then this protocol found the route according to the demand of the nodes and then creates the connection in sequence to send and receive the packet. In this, the source node begins the route discovery phase. This is also called as source routing protocols. Under reactive protocol many protocol are available.

\subsubsection{DSR}

DSR dynamic source routing protocol this is on demand routing protocol and it is mainly based on the concept of source routing. DSR is basically used source routing but it cannot use relaying on routing table at every device with in a network. The header of the request contains all the information about the path which is start from a sender to receiver. If a new packet is made to some other node destinations then DSR take the information of the packets header. A source route giving the sequence number and number of hopes which that packet follows. The nodes have to maintain the caches of routes which contain the source route and there route cache is update frequently, in this way new route are learned.

\subsubsection{AODV}

AODV Ad hoc on demand distance vector routing protocol is advanced version of DSDV. [3] The key difference between AODV and DSDV [4] the route is only established when any node want to communication or want to send some data to another node but DSDV maintain all route within the network. In AODV when any node (source) want to send data to another node (destination) then it start a path discover process to find the suitable path. Path is selected on the basis of different parameters. This path discovery process has one route request (RREQ) which is broadcast in the network. The RREQ go the neighbor of sender and further neighbor to neighbor. By doing so it reaches the destination and the destination node send route reply (RREP). In this way route established and data will start flowing from source to destination.

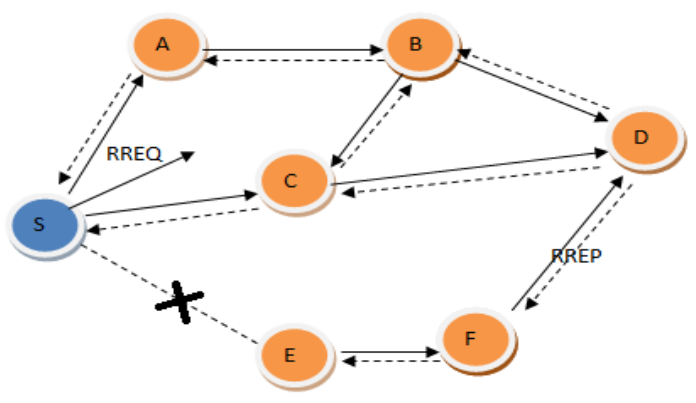

Figure 1: AODV Protocol

In figure 1, there are one source node $(\mathrm{S})$ and one destination node (D) and 5 intermediate nodes (A, B, C, E, F). First S broadcast the route request to all its intermediate nodes. Each and every node maintains sequence number and broadcast id itself. Broadcast id is not fixed it is vary according the nodes. When intermediate nodes have a route to the destination then it revert to route reply with corresponding sequence number. If nay intermediate node moves from its current place to some another place then it inform it neighbored node that a "link is failed" then the neighboring node pass this message to another neighboring node and so on until this message not reach the source node in this way link failure occur in a network. if sender node still need the link then it re-broadcast the request in a system

\section{CHALLENGES WITH MOBILE ADHOC NETWORK}

MANET is mainly used in the fields on which other type of communication are not applicable or sense to be impractical for example battle field, emergency rescue operations and in disaster situation [5] so in their field the MANET nodes forms a dynamic topology and remain with some limit range. So there is some issues in MANET:

A. Mobility: mobility of some nodes is very much higher as compared to other which result in link failure or energy of node drain at very quick so link failure occur or congestion problem arise .so load on one node increase.

B. Power: In MANET power is one of the major problem. In network all the nodes have its own power, some time any node has more load on it .so the consumption of power or energy is higher as compare to other node so that it result a link failure.

C. QoS: when we get everything according to our need from a network than QoS is fine .but in MANET there are several issues like mobility, packet loss, energy, delay variation so in MANET everything is not going according to our need and assumption so QoS is compromised.

D. Security: In MANET is not much secured networks, security remain always an issue in MANET. So there are many attacks (Black hole attacks, jellyfish attack) etc.

\section{AOMDV Protocol}

AOMDV Ad hoc on demand multipath distance vector routing protocol is based upon the AODV protocol. [6] It consists multipath, it is reactive protocol. The main key 
differences between AODV and AOMDV have multiple paths instead of single path between source to destination as in AODV. The multiple paths in AOMDV are grunted to be loop free and disjoint. When a AOMDV protocol found the various path then it make on table where the routing path are stored sender node choose one path for sending data according to the time stamp, if this path is broken mean link failed then the another alternative path is selected which is stored in routing table. every route has a specific time out so that congestion cannot occur in a system and hello message are broadcast after a specific time so that expire route can be eliminate. [8] AOMDV has three main different aspects than other on demand multipath protocol. These three different aspects are in AOMDV inter nodes coordination is not higher. secondly the alternative route are disjoint without and use of source routing and last one that the path which are computed by AOMDV have minimal additional overhead over AODV.

The source node sends a route request to all its neighbor red nodes in the form of flood. [9] Route request has two main parameters one is hope count and another one sequence numbers. With the help of these parameters loops can be avoided.

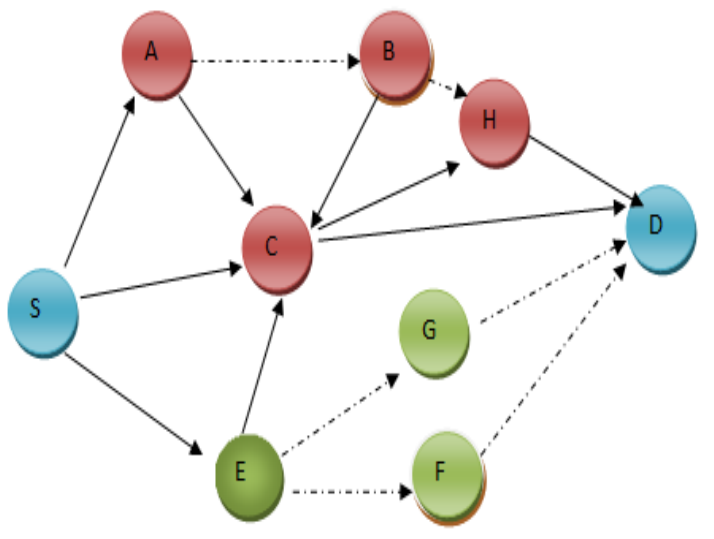

Figure 2: AOMDV Protocol

In figure 2, there are one source node $(\mathrm{S})$ and one destination node (D) and 7 intermediate nodes (A, B, C, E, F, G, H).like AODV first send a route request to all the neighboring node .which node find the destination that node route reply to the source node if there is any link failure exist than the alternative path is use for transmission of data.

\section{LITERATURE REVIEW}

Young j. Lee, George F. Riley et al. for improving load balancing. In this technique they focus on workload on node. Set on minimum and maximum threshold value for workload, When a route request RREQ is send by a sender it only goes through the nodes which are having workload value in between maximum and minimum threshold value.[10] In this way load is balanced within a network and packet latency, routing overhead is reduce.

Rachida Aoudjit, Malika Belkadi et al. Based upon the clustering a new algorithm which is a load balancing in nature is purposed. In this algorithm nodes cluster head subnets are selected and some load is maintain with the cluster overheads by which the cost of communication is reduced. [11] The main purpose of doing so is to reduce the time of processing tasks by spreading the work load within the node and to increase the time of life of node which is previously overloaded.

Sreenivas B.C, G.C. Bhanu Prakash et al. are telling about congestion control is a main problem in mobile networks.[12] So try to detect the congestion control problem in this paper using technique based upon the link layer providing method transmission control protocol. The congestion control method provided by Transmission Control Protocol (TCP) is specially designed for wired networks. This is considered of congestion control design of Link-Layer wireless networks, where the bandwidth and delay measured at each node along the path. Based upon the calculated values the receiver calculates the newly size window and transmits this information to the sender as feedback. The sender behavior is altered correctly. The proposed method is also reliable with standard TCP.

Archana Shukla, Sanjay Sharma et al. introduced load balancing algorithm in queue length based multipath Routing. [13] AOMDV protocol with queue length based which help to decrease the congestion by using non congestion route to send message, packet and move the load. In other word paths which exist in the network have long life and nodes have small queue length. Queues are selected for the packet routing along them. AOMDV protocol give the identification of the possible multiple node path start the source to destination and path identify based upon the performance of the nodes.

P.Sivakumar, Dr.K.Duraiswamy et al A new QoS routing protocol based on load distribution algorithm.[14]This algorithm calculate the cost metric which is based upon the load on any link in the network. The higher priority traffic is routed over the lightly loaded links if there is no real time traffic then the normal traffic is routed over this lightly loaded links. In this way end to end delay decrease and performance of both traffic getting better.

Sunsook Jung et al. "for the improving of MANET and efficient energy their main point of area is workload balancing and the energy constraint routing protocols.[15]The introduced the new routing protocol in which the adaptive load balancing technique to the MANET routing is employed. This also comes with node caching. A new application of which is having metrics of energy efficiency to the MANET routing protocols which is for energy efficient evolution of protocol in case of limited supply.

\section{CONCLUSION}

Twenty first century is digital era. There are lots of digital devices which are operatively on different frequencies. Mobility factor is adopted by various devices so every device is movable and communicate with each other without the help of wire. So In wireless media MANET is scheme which is widely used. In this nature different nodes move independently in various directions and sharing the data with each other, on the other hand there are some problems occur in this type network like problem with energy of node and nodes are overloaded with data in some cases. This paper is focused upon different routing like Proactive routing protocol (DSDV, OLSR and WRP), Reactive routing protocol (DSR, TORA, AODV) and some challenges in MANET. During data transmission there is a problem of link failure in MANET which decreases network performance and reliability. In the previous type various techniques had been proposed for load balancing. The most advanced and energy efficient technique is multipath routing. In Future to remove the link failure problem in AOMDV protocol Based upon the novel technique. 


\section{ACKNOWLEDGEMENT}

I am grateful to Lovely Professional University for providing me support and infrastructure to complete this paper

\section{REFERENCES}

[1] Mohit Kumar and Rashmi Mishra "An Overview of MANET: History, Challenges and Applications" Indian Journal of Computer Science and Engineering, Vol. 3 No. 1 Feb-Mar 2012

[2] Azzedine Boukerche, Begumhan Turgut "Routing protocols in ad hoc networks: A survey" Computer Networks - COMPUT NETW , vol. 55, no. 13, pp. 30323080, 2011

[3] Patil V.P “ Efficient AODV Routing Protocol for MANET with enhanced packet delivery ratio and minimized end to end delay" International Journal of Scientific and Research Publications, Volume 2, Issue 8, August 2012.

[4] Er.Punardeep Singh, Er.Harpal Kaur " Brief Description of Routing Protocols in MANETS And Performance And Analysis (AODV, AOMDV, TORA)" International Journal of Advanced Research in Computer Science and Software Engineering,Volume 2, Issue 1, January 2012.

[5] Aarti and Dr. S. S. Tyagi " Study of MANET: Characteristics, Challenges, Application and Security Attacks" International Journal of Advanced Research in

[6] Computer Science and Software Engineering, Volume 3, Issue 5, May 2013

[7] Mina Vajed Khiavi, Shahram Jamali "Performance Comparison of AODV and AOMDV Routing Protocols in Mobile Ad Hoc Networks" International Research Journal of Applied and Basic Sciences , 2013.

[8] Yumei Liu, Lili Guo,Huizhu "Energy Efficient ondemand Multipath Routing Protocol for Multi-hop Ad Hoc Networks" IEEE,2008.

[9] Chang-Woo Ahn "A Node-Disjoint Multipath Routing Protocol Based on AODV in Mobile Ad Hoc Networks"
Information Technology: New Generations (ITNG), 2010 .

[10] N.Jaisankar and R.Saravanan "An Extended AODV Protocol for Multipath Routing in MANETs" IACSIT International Journal of Engineering and Technology, Vol.2, No.4, August 2010

[11] Young j. Lee, George F. Riley "A workload-Based Adaptive Load-Balancing Technique for Mobile Ad Hoc Network" IEEE Communications Society 2005.

[12] Rachida Aoudjit ,Malika Belkadi et al. "Load Balancing :An Approach Based on Clustering in Ad Hoc networks" Journal of Computing and Information Technology, 2009.

[13] Sreenivas B.C G.C. Bhanu Prakash K.V. Ramakrishnan, "L2DB-TCP: An adaptive congestion control technique for MANET based on link layer measurements, IEEE International Advance Computing Conference, 2013.

[14] Archana Shukla, Sanjay Sharma "Queue Length Based Load Balancing Technique using with AOMDV protocol In MANET" International Journal of Scientific \& Engineering Research, Volume 4, Issue 10, October2013.

[15] P.Sivakumar, Dr.K.Duraiswamy “A QoS Routing Protocol for Mobile Ad Hoc Networks based on the Load Distribution" IEEE,2010.

[16] Sunsook Jung et. al."Energy Efficiency of Load Balancing in MANET Routing Protocols" Sixth International Conference,IEEE, 2005

[17] Gagandeep Kaur et.al, "A new Energy Efficient Queue based Multipath Load Balancing in Adhoc Network", IEEE, 2014

[18] Mohammad Amin Kheirandish Fard "Enhancing congestion control to address link failure loss over mobile ad hoc network" International Journal of Computer Networks \& Communications (IJCNC) Vol.3, No.5, Sep 2011. 